\title{
The HWWP, a refined IVA-Kano model for designing new delightful products or services
}

\author{
Sabina Alina Potra, Monica Izvercian, Adrian Pavel Pugna and Jens Jörn Dahlgaard \\ Journal Article
}

Tweet

N.B.: When citing this work, cite the original article.

This is an electronic version of an article published in:

Sabina Alina Potra, Monica Izvercian, Adrian Pavel Pugna and Jens Jörn Dahlgaard, The HWWP, a refined IVA-Kano model for designing new delightful products or services, Total quality management and business excellence (Online), 2017. 28(1-2), pp.104-117. Total quality management and business excellence (Online) is available online at informaworldTM:

http://dx.doi.org/10.1080/14783363.2015.1050168

Copyright: Taylor \& Francis (Routledge): SSH Titles http://www.routledge.com/

Postprint available at: Linköping University Electronic Press

http://urn.kb.se/resolve?urn=urn:nbn:se:liu:diva-136225

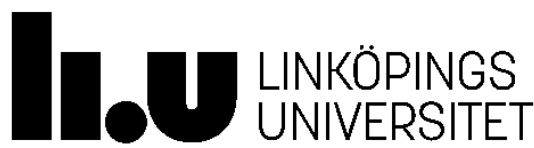




\title{
The HWWP, a refined IVA-Kano Model for designing new
}

\section{delightful products or services}

\author{
Sabina Alina Potra a*, Monica Izverciana ${ }^{a}$, Adrian Pavel Pugna ${ }^{a} \&$ J ens J örn Dahlgaard ${ }^{b}$ \\ ${ }^{\text {a }}$ Faculty of Management in Production and Transportation, Polytechnic University of Timisoara, \\ Timisoara, Romania \\ ${ }^{b}$ Department of Management and Engineering, Linköping University, Division of Quality Technology \\ and Management, Linköping, Sweden
}

*Corresponding author e-mail: sabina.potra@upt.ro

\begin{abstract}
For the last decade, companies have tried to survive in a continuous competitive global marketplace with informed and demanding customers for first-time-right delightful products and services. The present paper tries to answer the simple corporate question "How to design a new product for customer delight?” by exploring the relevant design requirements managers need to take into consideration for corporate strategic decision making. After examining the ongoing debate regarding the theory of attractive quality, the Health Weapon Wealth Prospect (HWWP) model is proposed for new product or service design, which relates Maslow's hierarchy of needs with the Kano methodology, importance of customer wants and the customer satisfaction coefficient. The result represents a theoretical contribution to the further development of the Kano model and a starting point for future explanatory research.
\end{abstract}

Key words: customer delight; quality attribute; hierarchy of needs; customer satisfaction; importance degree of customer wants; IVA-Kano model; value-added activity

\section{Introduction}

Customer satisfaction is one of the key elements of a company's financial performance and profitability (Anderson and Fornell, 1994). It is also related to the fulfilment of implicit and 
explicit customer needs by a product or service attributes (Tontini, Søilen and Silveira, 2013). Transforming the voice of the customer (VOC) into design requirements for satisfying the target group may help the company capture the largest share of the market (Yang and ElHaik, 2008).

In an extremely competitive global marketplace, a firm's success resides not only in satisfying customers, but delighting them (Oliver, Rust and Varki, 1997) for exceptional behavioural consequences such as loyalty or positive word-of-mouth, through the creation of value (Yang and Sung, 2011). Managers cannot start the design process without having a clear image of the attributes which will differentiate and create added value for their new product or service in the marketplace. Therefore, needs and expectations of future clients need to be listed, properly visualized and discussed before transforming them into design requirements. This list is usually realized by applying the Kano model of product attributes (Kano, 1984) which influences customer satisfaction and the Kano questionnaire for classifying customer requirements.

In the last 30 years, we have witnessed an exploration and an explosion phase of research in the area of the theory of attractive quality. Witell, Löfgren and Dahlgaard (2013) argue that further development of the Kano methodology is necessary for creating new and attractive products. In this line of reasoning, after a thorough analysis of the literature presented in the next chapter, the authors propose a theoretical contribution to the ongoing debate about the Kano methodology. The HWWP model measures customer quality attributes for a new product or service successful design in the light of customer importance of wants and customer satisfaction. It visually outlines customer quality attributes situated in four different domains which help specialists understand their position in the customer's mind. In the same time, this proposed model represents a useful tool throughout the new product's lifecycle. 
The model's theoretical foundation is explained with the help of a case study which envisages its practical usability for business performance. The methodology, results and discussions of the case study expose the HWWP's implications in managerial strategic decision making. The last section concludes the main contributions of the paper and paves the way for future research in the area of the theory of attractive quality.

\section{Theory of attractive quality debate}

Kano et al (1984)'s theory of attractive theory started as an attempt to better explain the roles that different quality attributes play for customers when desiring a product or service. A methodology was constructed for theory application which classifies quality attributes in one of six quality dimensions based on customer questioning regarding the presence or absence of a product or service feature.

If the feature finds itself in the A-attractive category, the customer has not thought about this characteristic but he likes the idea if it comes as a surprise. Attractive features are the ones that differentiate renowned brands from competition. If attractive means not expected, $O$ - one-dimensional refers to desired features the user is willing to pay for. The $M-$ must-be category is an expected feature, the consumer assumes it as a basic requirement. The $I-$ indifferent category represents a feature which has no influence on customer satisfaction or dissatisfaction and $R$ - reverse category expresses a backwards influence on customer satisfaction.

As pointed out by Witell, Löfgren and Dahlgaard (2013), research in this area has seen three different phases: an emergence, an exploration, and an explosion of research articles and debates regarding the Kano model. We consider ourselves still remaining in the explosion phase, where several debates have taken place regarding the classification of quality attributes. 


\section{Quality attributes - assignment in a category}

In the analysis phase of the Kano questionnaire, when two categories were seen as close to one another for a single attribute, researchers developed different solutions. Matzler (1996) used a special evaluation rule "M>O $>\mathrm{A}>\mathrm{I}$ " for a clear quality attribute category assignment. Newcomb and Lee (1997) classified the attributes in this situation as a combination, and Kano (2001) proposed a new approach regarding an attribute with two strong categories, talking for the first time about quality attributes’ dynamics. Thus, the lifecycle of a quality attribute states that it will change in time from being indifferent, to attractive, one-dimensional and ultimately must-be (Löfgren and Wittel, 2005). Each new Kano refined model must take into consideration this lifecycle, even when designing a new product from scratch.

\section{Quality attributes - classified based on importance}

It has been observed that quality attributes affect customer satisfaction differently. Although the Kano model has many uses, Yang (2003) considered it inefficient in identifying the rate of importance for each specific attribute. Martensen and Grönholdt (2001) classified quality attributes emphasizing the importance of customer wants. The Importance-Satisfaction model (IPA) has also identified the importance degree of each attribute as one criterion for its matrix. By keeping the importance degree customers give to specific attributes, we are able to understand which attributes are minimum requirements and which can be ignored.

Tontini, Søilen and Silveira (2013) argue that it is extremely important to avoid customer dissatisfaction by achieving adequate performance of must-be attributes before offering attractive or one-dimensional attributes. Only in this manner the one-dimensional and attractive attributes will positively affect customer satisfaction. At the same time, Moorman (2012) suggests that smart money is invested in one-dimensional and attractive features 
because those are the attributes which capture the hearts and minds of customers, triggering delight. The question appears: "How to order and understand customer quality attributes and not dissatisfy customers but delight them?”

\section{Refined attractive quality models}

In the attempt to answer this question, Yang (2005) has developed a refined Kano model categorizing quality in four domains (attractive, one-dimensional, must-be, and indifferent), each with two subcategories. This approach was a step closer to a Kano methodology development, because the traditional six categories have been reduced to four, discarding reverse and questionable elements with no strategic importance.

Kuo, Chen and Deng (2012) proposed a mix between the Kano model and the ImportancePerformance Analysis (IPA). Nevertheless, the IPA-Kano model has limited practical usability due to the fact that the three series of attributes (must-be, one-dimensional, and attractive) are introduced in a two variable diagram (importance and performance) as circles. The circle with the highest perimeter is represented by attractive attributes, this implying that they can have higher importance than must-be attributes, which is not the case.

\section{The HWWP model for new product or service design}

The refined attractive quality models discussed, even though interesting, are not suited for a product or service design from scratch where we do not have previous performance knowledge. Due to the fact that we are not able to measure previous performance for a new product or service attribute, we must take into consideration its value-added potential, Berger et al. (1993)'s positive better numbers in relation with customer satisfaction. 
Value-added activities or product/service characteristics enhance customer delight because this positive emotional state results from having one's expectations exceeding to a surprising degree (Rust and Oliver, 2000). Therefore, value triggers satisfaction and delight, becoming critical for success.

All attributes researched for a specific new product or service will therefore pass through the reading glass of its customers regarding their importance degree and the value it adds for their satisfaction, taking into consideration the quality attributes lifecycle for strategic design. Therefore, the proposed model is introduced in a two variable diagram formed by importance of customer wants and the value added potential of specific quality attributes.

\section{The origin of the HWWP model in Maslow's hierarchy of needs}

We have compared Yang (2005)'s four main quality elements and Kuo, Chen and Deng (2012)'s series (health, war and treasure) with Maslow (1943)'s hierarchy of needs, and the outcome envisages the main domains of our model and the guidelines for future quality attributes assignment (Fig.1).

Extrapolating, each firm can become a warrior in the global battlefield for market share. Must-be attributes represent the corporate product's basic needs for survival, the functional needs envisaged by Salado and Nilchiani (2013) as the expression "I want it to work" and Kano et al.(1984)'s necessity factors. These basic needs were related to psychological health by Lester et al. (1983). Without must-be features, the product or service manifests sickness and potential death. A normal state is assured by meeting these needs. Without this level fulfilled, we cannot enrich the offer and scale success. 


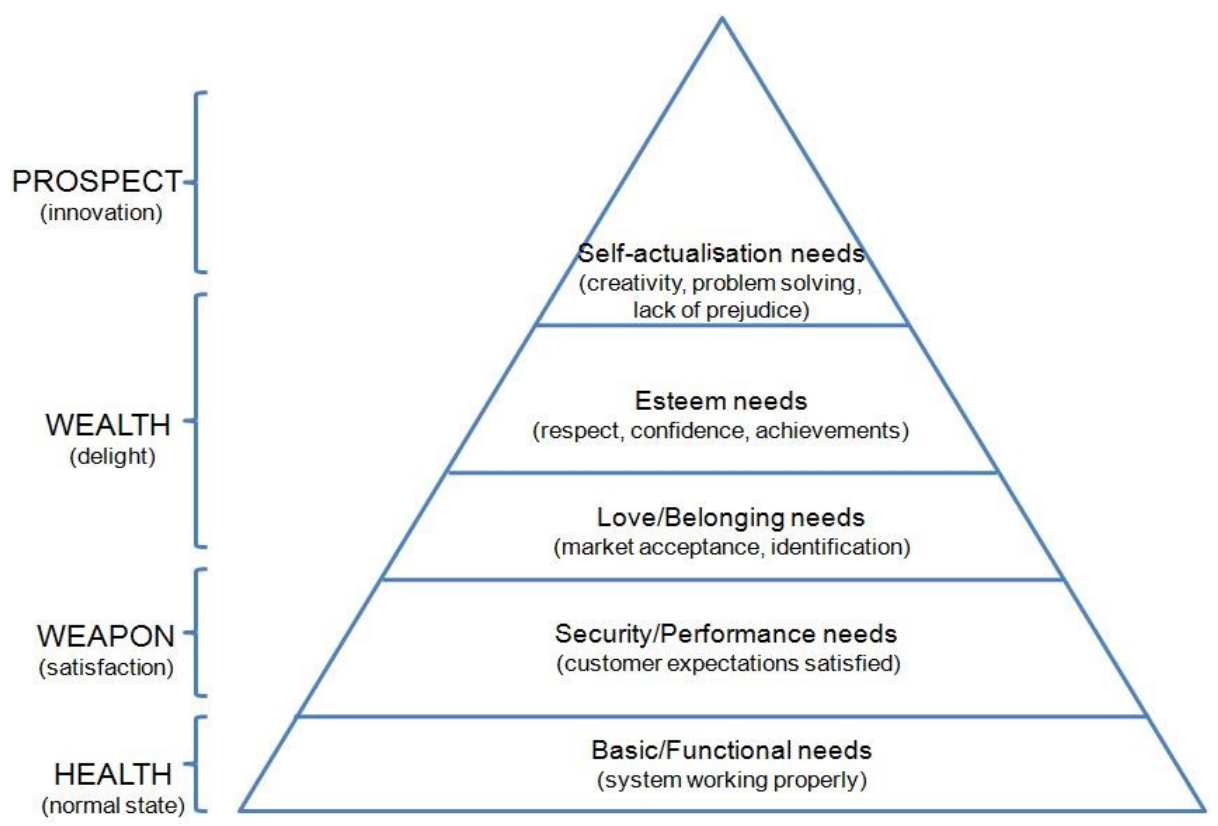

Figure1. The HWWP's domains and Maslow's hierarchy of needs

Thereby must-be features do not offer customers what they desire and demand, but are important and necessary for ascending to a higher degree in the hierarchy of needs.

D’Addario (2013) argues that individuals, and likely organizations, are not capable of successful development prior to meeting their primary security needs. Salado and Nilchiani (2013) are referring to this type of needs as related to performance and define them by the expression: "Now that it works, I would like that ..." Similarly, Kano et al. (1984) call them performance factors. In the light of the above-mentioned research, security is considered a protection from the risk of being injured or killed through performance. Therefore, safety or security needs are translated into one-dimensional attributes, representing a firm's weapons against rival companies. These attributes provide customer satisfaction.

But in such a competitive global environment, sustainable companies need to delight their customers for a secure and desired market share. Weapons wear out, and the firm must provide enough wealth to sustain a new weapon division because we already know that the feature which delights users today becomes what they demand and expect tomorrow (Moorman, 2012). Indeed, in time, customers will start to consider the elements that triggered 
delight as normal. When you have attractive attributes you possess wealth; when you have wealth (money and fame), you have assured market acceptance (love needs) and respect (esteem needs).

What about self-actualization needs? Even if we find ourselves in the design stage of a new product or service, we must think about the future. A firm can reach the top of the pyramid with creative and adaptable thinking regarding prospect attributes, because successful attributes are often indifferent before they become attractive (Nilsson-Witell and Fundin, 2005). Thus, time dynamics consumes a company's wealth, wears out its weapons and endangers its health. Firms must think about the future even when designing a new product and should maintain prospect features in a continuous research and development stage.

Due to quality attributes' dynamics, an attribute will change over time from being a satisfier to a "dissatisfier” (Löfgren and Wittel, 2005), from an attractive to a must-be feature. This lifecycle can be applied to Maslow's hierarchy of needs. A photo camera on a mobile phone was an attractive attribute determining an esteem need in the early 2000s, becoming quickly one-dimensional and than a must-be functional feature. Nowadays most mobile phones, even inexpensive ones, are sold with a camera. It is considered a must-be feature which assures a certain degree of health for the producing company. Quality attribute categories change with time as customer needs change with different offerings and lifestyles. In the same way, a company must adapt its weapons and wealth to respond quickly to market needs.

\section{The four domains of the HWWP model}

The complexity of each domain is revealed by the stages it comprises (Fig.2). 


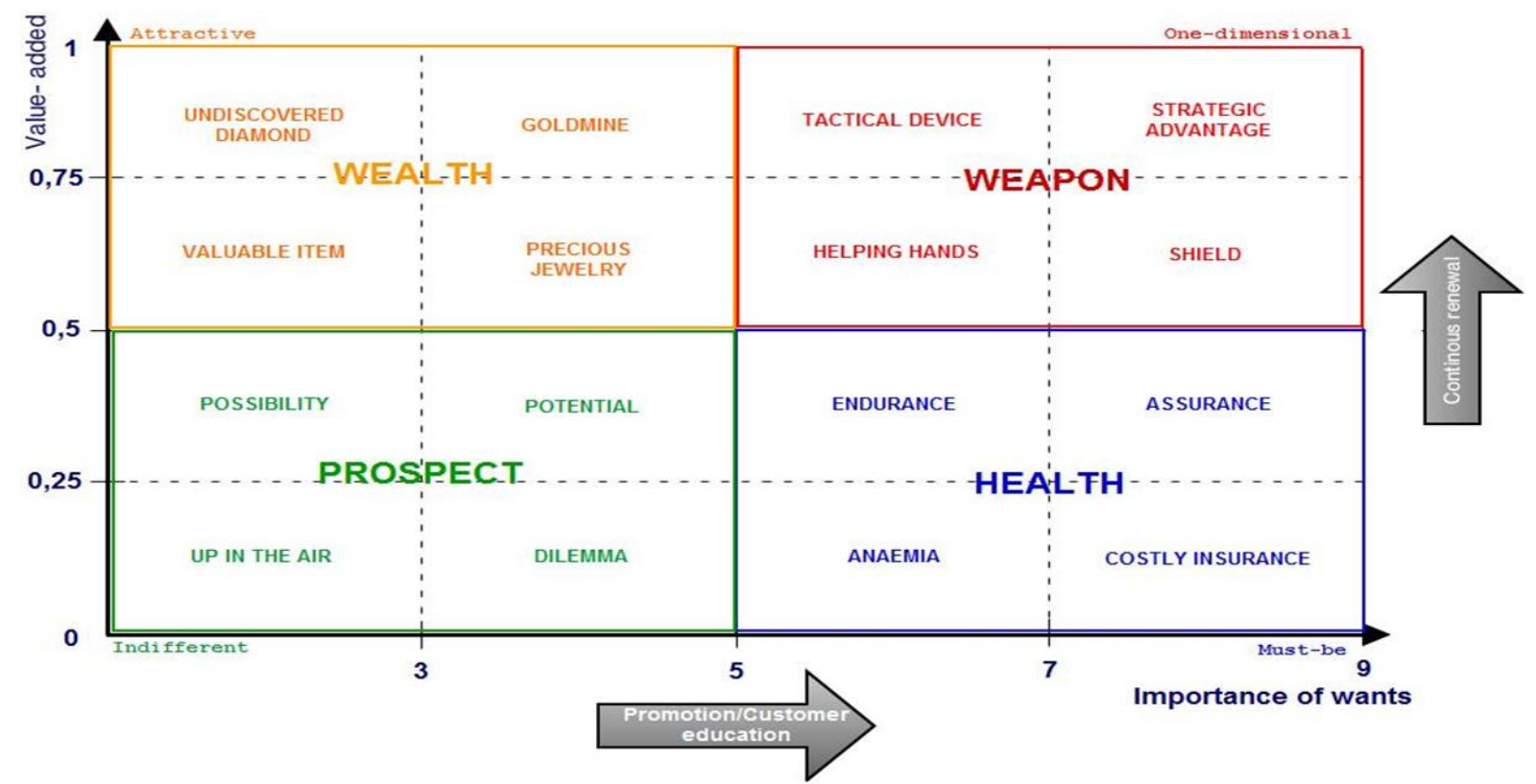

Figure2. The HWWP - refined IVA-Kano Model

The HWWP model measures customer importance on a 3-5-9 scale where 1 - „Not at all Important” and 9 - „Extremely Important”, and value-added characteristics with the help of the customer satisfaction coefficient (Berger et al., 1993).

Health domain (high importance, low value-added, must-be characteristic)

This first domain refers to Herzberg, Mausner and Snyderman (1959)’s “motivation hygiene theory” and represents, as Kuo, Chen and Deng (2012) suggest, attributes essential to enterprises as health is to the human body. Depending on the importance and value-added variables, these must-be characteristics are classified into four groups:

- costly insurance (7-9 very high importance, $0-0.25$ very low value-added) - a product or service characteristic situated in such a category has to be maintained or insured at all costs solely because insufficiency may lead to problems which could disturb the new service's potential success. It does not supply enough value to assure company growth, representing only a costly requirement for existence; 
- anaemia (5-7 high importance, 0 - 0.25 very low value-added) - because these attributes do not cause extensive dissatisfaction and do not provide enough value, the investment in them may cause a sickly state and may exhaust resources. It is advisable to avoid such category attributes for new products and services;

- assurance (7-9 very high importance, 0.25 - 0.5 low value-added) - must-be characteristics from this category guarantee a basic level of efficiency. With some sort of value and a high importance, their provision is extremely important for the soundness of the newly designed business;

- endurance (5-7 high importance, 0.25 - 0.5 low value-added) - do not affect the service or product future survival because they are not a fatal quality, but they may be important if the value-added variable is promising and the cost is reasonable.

\section{Weapon domain (high importance, high value-added)}

The second domain describes the four main strategies a company can use for new product or service differentiation. They represent weapons against possible competitors which secure a good position in the marketplace. These attributes are important and provide value for the customers, the perfect mix to ensure future gains. Depending on the importance for customers and the value they add to the service, the categories of this one-dimensional domain are:

- shield (7-9 very high importance, 0.5 - 0.75 high value-added) - the very high importance of these attributes ensures a comfortable place of the product or service regarding possible competitors. They are safeguard attributes, which cannot win a war by themselves, but keep the product or service affront;

- helping hands (5-7 high importance, 0.5 - 0.75 high value-added) - these specific attributes advocate customer's desires. Even if importance is not critical, they are appreciated and their fulfilment is welcomed, producing value and satisfaction. The significant concern 
regarding users produces a comfortable state and ensures a place at the rich man's table in the mind of the consumer;

- strategic advantage ( 7-9 importance, 0.75 - 1 very high value-added) - this strategy comprises the product or service main development reason, the idea from which the new offer originated. Without at least one such attribute a company's new product or service is doomed to failure. The very high importance and the value it adds to the service make this category the most relevant of the entire model;

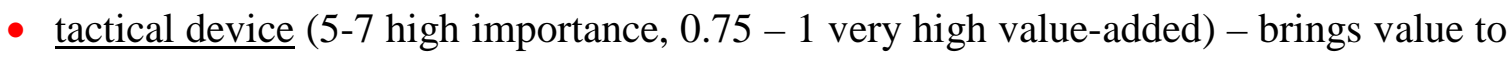
the product or service, satisfying customers in a way in which it supports the strategic advantage.

Wealth domain (low importance, high value-added)

The third domain of the IVA-Kano model can be easily represented as a treasure hunt experience because, as Kuo, Chen and Deng (2012) argue, people can live without jewellery, but are happier when they find and own some. In the same way, insufficient attractive characteristics do not lead to customer dissatisfaction, but they reserve a delightful experience for the one who finds and exploits them. And because the loyalty curve is relatively flat within the zone of satisfaction and climbs rapidly as a result of delight or exceptionally high satisfaction (Dick and Basu, 1994), attractive high valued characteristics represent the wealth of an offer. The four categories it comprises are:

- precious jewellery (3 - 5 low importance, 0.5 - 0.75 high value-added) - this category depicts attractive attributes, which add value to customer experience and therefore induce an emotional state, engaging the user with the new product or service in the same way in which precious jewellery triggers an emotional response in the person it is offered to; 
- valuable item (0 - 3 very low importance, 0.5 - 0.75 high value-added) - the valuable item category represents attractive characteristics which are limited to the conception of the product or service, but with time they may be developed and lead to future success. These attributes constitute the basis of a continuous renewal of the newly designed product or service;

- goldmine (3 - 5 low importance, 0.75 - 1 very high value-added) - fascinate customers. With adequate promotion and customer education, attributes from this category can literary become a goldmine. When designed, the company specialists must estimate the impact of such an attractive option and invest adequately as to transform it in a strategic advantage in years to come. This represents a real strategic thinking in the conception phase of a new product or service;

- undiscovered diamond ( 0 - 3 very low importance, 0.75 - 1 very high value-added) - if resources allow, an unimportant attribute with high value may be turned into a radical innovation which in time can develop tactical or strategic advantages as a weapon in the marketplace. A new product needs not only well-defined and acknowledged characteristics but also undiscovered or raw attributes in a continuous renewal path for competitive advantage. Thus, we must conceive something suitable today which will develop into something extraordinary tomorrow.

\section{Prospect domain (low importance, low value-added)}

The last domain envisages a quadrant with four prospective categories. These items do not represent a priority, some may not be taken into consideration in the conception and design stage of a new product or service, but a small amount with the right corporate strategy can become future competitive weapons. The categories of the prospective domain are: 
- $\underline{\text { dilemma }}$ (3 - 5 low importance, 0 - 0.25 very low value-added) - these characteristics have a certain amount of importance for the customer but lack value-added advantages. In the designing stage of the new product or service there will be no dilemma whether to include this attribute or not. It is not advised to spend money on something with so little worth, but with adequate promotion or renewal strategies, the respective attribute can become a possible weapon in the future;

- up in the air ( 0 - 3 very low importance, 0 - 0.25 very low value-added $)$ - such an attribute can be easily excluded in the majority of cases, because it triggers neither satisfaction nor dissatisfaction. In extremely rare situations such an "up in the air" characteristic can gain some value;

- potential (3 - 5 low importance, 0.25 - 0.5 low value-added) - potential attributes represent the most interesting items of this domain because they can easily be transformed into weapons or wealth. If not costly to implement, it is advised to include them in the new product or service design;

- possibility ( 0 - 3 very low importance, 0.25 - 0.5 low value-added) - the scarce added value of these attributes and the very low importance for customers makes them easy to neglect in the conception of the product, but have a possible importance in future development ideas.

The horizontal arrow below the importance of wants variable - "promotion/customer education” - represents a possible improvement strategy which, as Kuo, Chen and Deng (2012) have argued, may help the newly developed product or service to maintain its Six Sigma efficiency standard and the educated and informed customer to appreciate valuable experiences. It also envisages a considerable marketing and PR effort. With the help of this strategy, the present detected attractive or prospective attributes can become valued and extremely useful weapons against competition. 
Even if we are in the design stage of a new product, managers must always consider potential improvements for sustainable growth in years to come. Therefore, the vertical arrow - "continuous renewal" - serves as the main strategic objective of smart companies. They must always come up with something new or improved in order to delight customers through value-added processes. Continuous renewal may transform costly insurance in assurance or a shield attribute in a strategic advantage.

The HWWP model not only provides an overview of the new product or service's relevant attributes but also facilitates a managerial strategic thinking. For a better understanding of the model, we have implemented it in the design stage of a new shoe customisation service for a local shoe manufacturing company.

\section{Case study - implementing the HWWP model for a new customisation service}

In an attempt to add value to its offer, a shoe manufacturer aims to develop a customisation service for customer delight. The company wishes to address a younger target group and therefore needs an adequately designed service for selling and customising shoes.

\section{Methodology}

The target customer requirements regarding a possible customisation option have been identified starting from a questionnaire-based market research: ease of use, time optimisation, interesting design, interactivity, large number of options for customisation, large number of shoes to be customised, and several payment options. Due to the fact that the identified features were too general for an adequate understanding of the VOC, several possible service attributes have been developed, reaching a total number of 14 .

The Kano questionnaire has been built, based on a pair of two questions for each specific service characteristic to which the customer could answer in one of five different ways (Yang 
and El-Haik, 2008). Thereby, one question from each pair had a functional form (concerning the reaction of the customer if the product had that feature) and the second question had a dysfunctional form (concerning the customer's reaction if the product did not have that feature). The standard importance questionnaire has been used with the following scale: 1 (Not at all Important)... 9 (Extremely Important).

Before applying these questionnaires, an optimal proportional sample size has been established. People with ages ranging from 19 to 45, persons who demonstrate an increased online buying behaviour have responded to the questionnaires, both by mail (1/3 of cases) and by standard face-to-face oral interviews (2/3), totalling 164 individual valid responses.

Based on the Kano questionnaire, after taking into account the entire amount of responses, each service attribute was granted a category stated in a general table of results evaluated according to frequencies. The classification of quality attributes was tested through a t-test in order to compare the proportions of customers classifying a quality attribute to a specific quality category. The classification of the attributes is statistically significant, that is, 12 of them at $\mathrm{p}<0.01$ and 2 of them at $\mathrm{p}<0.05$.

The value-added criteria for the first variable of our model was analysed based on Berger et al. (1993)' s positive better average numbers which state whether customer satisfaction can be increased by meeting a certain quality attribute (customer satisfaction coefficient - SC). We consider that the SC coefficient represents the value an attribute adds to a service and therefore we analyse it according to relation (1)

$$
S \in \frac{A+O}{A+O+M+I}
$$

The positive SC coefficient ranges from 0 to 1 ; the closer the value to 1 , the higher the influence on customer satisfaction. But if it approaches 0, there is very little influence.

For the last variable of our model, we have developed the importance of wants questionnaire which has been distributed along with the Kano questionnaire. 


\section{Results}

Table 1 presents the Kano categories which emphasize the four main domains of our model, with the customer satisfaction results (SC) which outline the value-added of each new service attribute and the average importance intervals (we have computed the importance answers across all 164 respondents).

Table 1. Table of results

\begin{tabular}{|c|c|c|c|c|c|c|c|c|c|c|}
\hline $\begin{array}{l}\text { Customisation } \\
\text { requirements }\end{array}$ & A & $\mathbf{O}$ & $\mathbf{M}$ & I & $\mathbf{R}$ & $\mathbf{Q}$ & t-test & Category & $\begin{array}{c}\text { Value- } \\
\text { added (SC) }\end{array}$ & $\begin{array}{c}\text { Stated } \\
\text { Importance }\end{array}$ \\
\hline $\begin{array}{l}\text { information clarity } \\
\text { and concision }\end{array}$ & 7.4 & 29.2 & 47.6 & 14.5 & 0.6 & 0.6 & $\mathrm{p}<0.01$ & $\mathrm{M}$ & 0.37 & 7.3 \\
\hline ease of use & 18.4 & 49.7 & 20.8 & 11 & 0 & 0 & $\mathrm{p}<0.01$ & $\mathrm{O}$ & 0.68 & 7.2 \\
\hline $\begin{array}{l}\text { loading time } \\
\text { optimization }\end{array}$ & 13 & 43.8 & 21.6 & 19.1 & 1.2 & 1.2 & $p<0.01$ & $\mathrm{O}$ & 0.58 & 5.7 \\
\hline $\begin{array}{l}\text { fast order } \\
\text { confirmation }\end{array}$ & 13.7 & 43.5 & 25.4 & 16.7 & 0.6 & 0 & $\mathrm{p}<0.01$ & $\mathrm{O}$ & 0.57 & 6.1 \\
\hline modern design & 57 & 13.1 & 0 & 25.6 & 3.1 & 1,2 & $\mathrm{p}<0.01$ & $\mathrm{~A}$ & 0.73 & 4.6 \\
\hline product 3D format & 64.8 & 4.9 & 3.7 & 18.6 & 1.2 & 6.8 & $\mathrm{p}<0.01$ & A & 0.75 & 4.9 \\
\hline image rotation & 50 & 20.1 & 6 & 20.2 & 0 & 3.7 & $\mathrm{p}<0.05$ & $\mathrm{~A}$ & 0.72 & 4.4 \\
\hline $\begin{array}{l}\text { customisation } \\
\text { storage }\end{array}$ & 33 & 28.6 & 9.2 & 26.2 & 1.2 & 1.8 & $\mathrm{p}<0.01$ & $\mathrm{O} / \mathrm{A}$ & 0.63 & 3.9 \\
\hline $\begin{array}{l}\text { view of other's } \\
\text { customised orders }\end{array}$ & 30.2 & 12.3 & 4.3 & 50 & 2.5 & 0.7 & $\mathrm{p}<0.01$ & I & 0.43 & 3.7 \\
\hline $\begin{array}{l}\text { large number of } \\
\text { customisable shoes }\end{array}$ & 45.3 & 16.6 & 4.3 & 25.7 & 3.7 & 4.3 & $\mathrm{p}<0.01$ & A & 0.67 & 3.8 \\
\hline customising color & 39 & 34.1 & 15.3 & 9.2 & 0.6 & 1.8 & $\mathrm{p}<0.01$ & $\mathrm{O}->\mathrm{A}$ & 0.74 & 7.7 \\
\hline $\begin{array}{l}\text { customising leather } \\
\text { material }\end{array}$ & 35.6 & 31.3 & 7.4 & 24.5 & 0.6 & 0.6 & $\mathrm{p}<0.05$ & $\mathrm{O}->\mathrm{A}$ & 0.67 & 7 \\
\hline $\begin{array}{l}\text { customising } \\
\text { accessories }\end{array}$ & 39.6 & 29.3 & 7.9 & 20.8 & 0.6 & 1.8 & $\mathrm{p}<0.01$ & $\mathrm{O}->\mathrm{A}$ & 0.70 & 6.3 \\
\hline
\end{tabular}




\begin{tabular}{|l|l|l|l|l|l|l|l|l|l|l|}
\hline payment options & 32.9 & 23.2 & 20.1 & 23.2 & 0.6 & 0 & $\mathrm{p}<0.01$ & $\mathrm{O}->\mathrm{A}$ & 0.56 & 6.4 \\
\hline
\end{tabular}

Based on the results in Table 1, we have constructed the HWWP model for the shoe customisation service as stated in Figure 3.

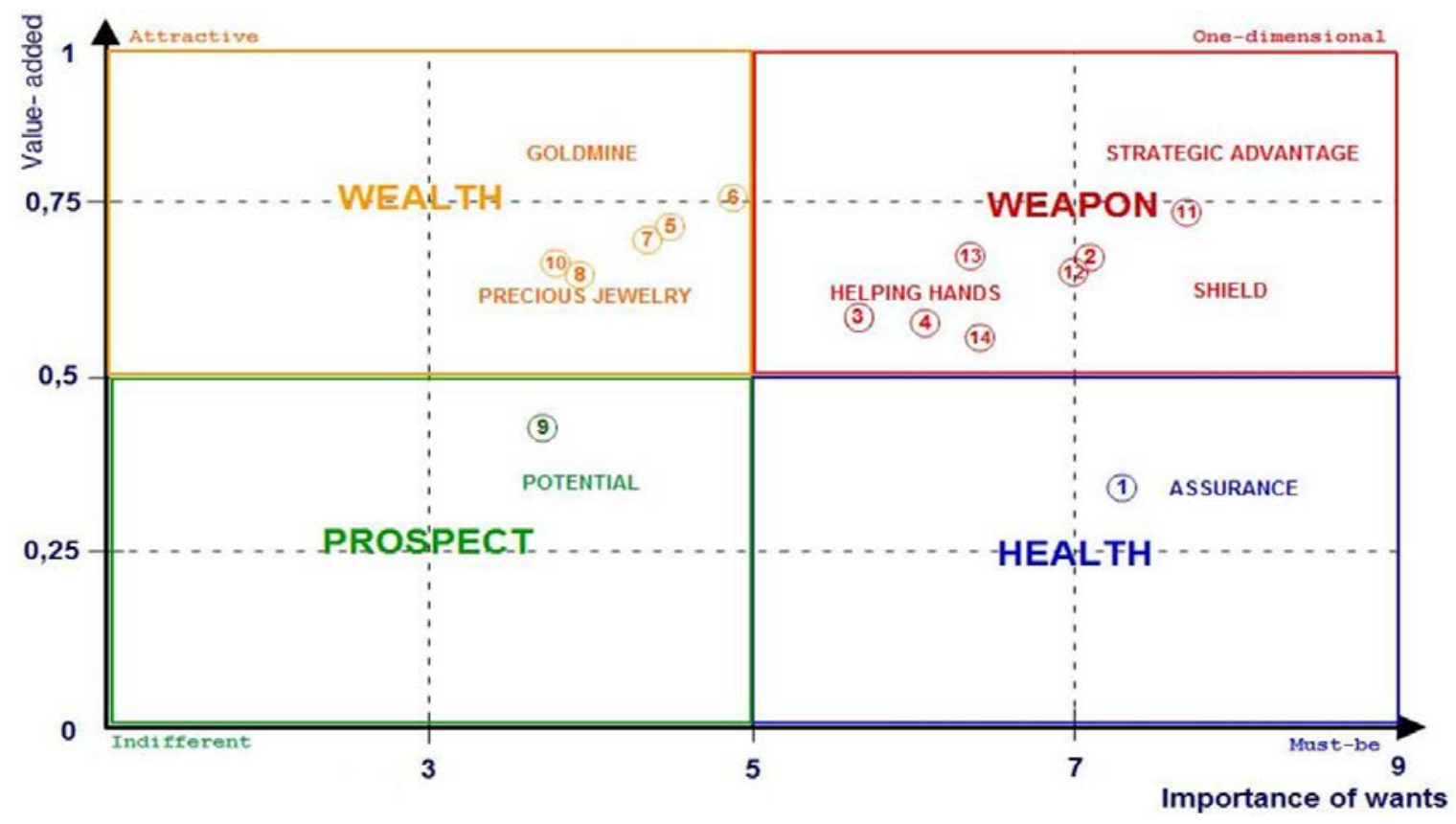

Figure 3. The HWWP model for the new shoe customisation service

\section{Discussions}

The first customer requirement, information clarity and concision does not have a very consistent influence on customer satisfaction, but if not fulfilled, it causes customer dissatisfaction especially in an online environment where information ambiguity determines a user to quit the platform in the majority of cases. Therefore this must-be attribute is placed in the health domain where it assures a steady condition. In future years the company can maintain this health attribute by cost efficiency strategies.

The ease of use is desired and represents a one-dimensional feature because consumers consider it important. Gadgets, links and other tools must be easy to use by usual individuals with medium online experience. In addition, it provides also increased value, becoming a 
relevant weapon in the battle for survival and excellence. In the future, by promoting the ease of use of their service, this attribute can become an effective shield against similar services.

Loading time optimization is a one-dimensional feature that every customer desires, situated in the future service’s “weapon department” as a helping mechanism for customer satisfaction. Once you click on a web page, you wish it loads instantly. But when designing a product as a whole, attribute interactions are critical. For the customisation option, we must take into consideration the fact that many images with high resolution may jeopardize the loading optimization.

When ordering a pair of shoes on the Internet, the customer desires a quick confirmation and also a very fast delivery. This service attribute must be standardized into a time frame that is optimal for both the company and the customer, but it must not exceed one day. If adequately designed and implemented the service will satisfy and differentiate the service from competition, as a "helping hand" for the client.

A modern design of the webpage where the customisation will take place is considered an attractive requirement, being situated in the wealth domain of our model as a precious attribute similar to jewellery. Therefore the customer will be delighted to visualize a fresh and innovative design, which will be pleased to work with. But if the company does not provide such a modern design, the customer may be satisfied with a classic one as well. The medium importance and pretty high value it adds to the new service are reason enough to include this characteristic to the new corporate offer if costs are low.

When customising a pair of shoes, a $3 D$ format is extremely attractive, as if finding a goldmine. The customer can see the model's details and its colour or material can easily be changed. It would be a plus for the company and especially for the new service to provide such a feature. Nevertheless the increased cost with its implementation may trigger debates. 
For understanding all the specificities of a model an image rotation option is very attractive. Combining the 3D format with a rotating image and a modern design, the service will be unexpected and surprising.

Viewing other's customisation orders has an influence on customer satisfaction, adding value to the experience. The majority of customers are indifferent to viewing other customer's customisation orders. This prospect attribute can be improved and implemented further on into the service, when weapons wear out, for a fresh new wealth element.

The possibility of customising all collections of the company is seen as attractive because it supplies wealth and delight. But we can easily notice that this attribute holds a low level of importance; this leads us to think that the company has a manoeuvring space, it can provide for customisation only shoes which are designed for promotion and not the entire collection.

When customising a pair of shoes, having the possibility to change their colour is seen as attractive in 39\% of cases and desired in 34\%. Therefore, it represents an attribute commuting from an attractive to a one-dimensional category. This weapon, when wisely used, can become a steady strategic advantage, retaining customers and satisfying their needs.

In the same way, customising leather material and adding accessories to a pair of shoes represent weapons and more specific helping hands for passionate users. In a few years, with adequate promotion and improvement, these attributes can become the firm's strategic advantage.

Last but not least, the multiple payment options attribute is considered one-dimensional, being situated in the weapon domain of the HWWP model. This feature may bring dissatisfaction if the company does not provide two or three payment possibilities. With increased ease of use options, the firm can transform it in a tactical advantage.

\section{Conclusions}


When designing a brand new product or service, companies want to have a first-time-right success. Therefore, they need to assess the voice of the customer (VOC) and visualize its quality attributes in a simple and suggestive manner.

Even if the majority of recent studies have failed to determine significant explanations of the theory of attractive quality, the authors have learned to merge interesting ideas from the “explosion phase” (Witell, Löfgren and Dahlgaard, 2013) and build on the foundations of the Kano methodology. The recent focus on Kano categories introduction and evaluation perspectives (Ipek Ek and Çikiş, 2013), on quality category transformation (Borgianni and Rotini, 2013), and on the need to create customer loyalty through delight (Högström, 2011) made the authors to rethink the Kano methodology for a delightful product or service design from scratch with an evaluation perspective (importance of wants and value-added quality for customer satisfaction), which adapts to category lifecycle transformations for continuous organizational strategic thinking.

Due to the fact that current measuring models for the voice of customer were not suited for the conception of a new corporate offer, the proposed HWWP model represents a managerial tool with easy to understand domains and suggestive categories for business excellence strategic thinking.

Future research will focus on the degree in which the model can be used for improvement of already launched products or services. In this case we must take into consideration key performance indicators related to a customer, marketing, and operational perspective.

\section{References}

Anderson E.W \& Fornell C. (1994). A Customer Satisfaction: Research Prospects, in R.T. Rust and R.L. Oliver (eds.) Service Quality: New Directions in Theory and Practice, pp.241269. SAGE Publications Ltd., London 
Berger C. et al. (1993). Kano's methods for understanding customer-defined quality, The Centre for Quality Management Journal, 2(4)

Borgianni Y \& Rotini F. (2013). Towards the fine-tuning of a predictive Kano model for supporting product and service design, Total Quality Management\& Business Excellence, 01/2013, DOI: 10.1080/14783363.2013.791119

D’Addario F. J. (2013). Influencing Global Risk Mitigation (Second Edition), Elsevier Inc., Oxford, UK, pp.1-14

Dick A.S. \& Bansu K. (1994). Customer loyalty: Toward an Integrated Conceptual Framework, Journal of the Academy of Marketing Science, 22(2), pp.99-113

Herzberg F., Mausner B. \& Snyderman B.B. (1959). The Motivation to Work. New York: John Wiley and Sons

Högström C. (2011). The theory of attractive quality and experience offerings, The Total Quality Journal, 23(2), pp.111-127

Ipek Ek \& Çikiş S. (2013). Integrating the Kano model into architectural design: quality measurement in mass-housing units, Total Quality Management\& Business Excellence, DOI: $10.1080 / 14783363.2013 .835898$

Kano N. et al. (1984). Attractive quality and Must-be quality. The Journal of the Japanese Society for Quality Control, 39-48, April

Kuo Y.F., Chen J.Y \& Deng W.J. (2012). IPA-Kano model: A new tool for categorizing and diagnosing service quality attributes, Total Quality Management\& Business Excellence, 23(78), pp.731-748

Lester et al. (1983). Maslow's hierarchy of needs and psychological health, The Journal of General Psychology, 109, pp. 83-85

Löfgren M. \& Witell L. (2005). Kano’s Theory of Attractive Quality and Packaging, Quality management Journal, 12(3), pp.7-20 
Martensen A. \& Grönholdt L. (2001). Using employee satisfaction measurement to improve people management: An adoption of Kano’s quality types, Total Quality management, 12 (78), pp. 949-954

Maslow A.H. (1943). A Theory of Human Motivation, Psychological review, 50(4), pp.370396

Moorman J. (2012). Leveraging the Kano Model for Optimal Results, UX Magazine, Article No.882, October 9, available at: http://uxmag.com/articles/leveraging-the-kano-model-foroptimal-results. Accessed: 31.07.2014

Newcomb J \& Lee M. (1997). Applying the Kano methodology to meet customer requirements: NASA’s microgravity science program, Quality Management Journal, 4(3), pp.95-110

Nilsson-Witell L. \& Fundin A. (2005). Dynamics of service attributes: A test of Kano’s theory of quality, International Journal of Service Industry Management, 16(2)

Oliver R.L., Rust R.T. \& Varki S. (1997). Customer Delight: Foundations, Findings and Managerial Insight, Journal of Retailing, 73 (Fall), pp.311-336

Rust R.T. \& Oliver R.L. (2000). Should We Delight the Customer?, Journal of the Academy of Marketing Science, 28(1), pp. 86-94

Salado A. \& Nilchiani R. (2013). Using Maslow’s hierarchy of needs to define elegance in system architecture, Procedia Computer Science, 16, pp.927-936

Tontini G., Søilen K. S. \& Silveira A. (2013). How do interactions of Kano model attributes affect customer satisfaction? An analysis based on psychological foundations, Total Quality management \& Business Excellence, 24(11-12) Special Issue, pp.1253-1271

Witell L., Löfgren M. \& Dahlgaard J.J. (2013). Theory of attractive quality and the Kano methodology - the past, the present, and the future, Total Quality management \& Business Excellence, 24(11-12) Special Issue, pp.1241-1252 
Yang C.C. (2003). Improvement actions based on the customers' satisfaction survey, Total Quality Management \& Business Excellence, 14(8), pp.919-930

Yang C.C. (2005). The refined Kano’s model and its application, Total Quality Management \& Business Excellence, 16(10), pp.1127-1137

Yang C.C. \& Sung D. (2011).An Integrated Model of Value Creation Based on the Refined Kano’s Model and the Blue Ocean Strategy, Total Quality Management \& Business Excellence, 22(9), pp.925-940

Yang K. \& El-Haik B. (2008). Design for Six Sigma: A Roadmap for Product Development. Mc Graw 